\title{
Agronomic properties and characterization of rice husk and wood biochars and their effect on the growth of water spinach in a field test
}

\author{
O.Varela Milla ${ }^{1}$, Eva B. Rivera ${ }^{1}$, W.-J. Huang, ${ }^{2, *}$, C.-,C. Chien ${ }^{3}$, Y.-M. Wang ${ }^{4}$ \\ ${ }^{1}$ Department of Tropical Agriculture and International Cooperation, National Pingtung University of Science and Technology, \\ Pingtung 91201, Taiwan. ${ }^{2}$ Department of Environmental Science and Engineering, National Pingtung University of Science \\ and Technology, Pingtung 91201, Taiwan. ${ }^{3}$ Industrial Technology Research Institute Tainan 734, Taiwan. ${ }^{4}$ Department of Civil \\ Engineering, National Pingtung University of Science and Technology, Pingtung 91201, Taiwan. *Corresponding author: \\ wjhuang@mail.npust.edu.tw
}

\begin{abstract}
This study compared the agronomic properties of rice husk biochar (RHB) and wood biochar (WB) and investigated their effect on the growth rate of water spinach in a field experiment. Each biochar type was tested at 5 different rates of 4.0, 3.0, 2.0, 1.0 and $0.5 \mathrm{~kg}^{\mathrm{m} 3}$, respectively. The results detailing the growth of water spinach showed that the application of rice husk biochar improves biomass production. The WB added to soil increased the plant weight of water spinach by increasing the root size and leaf width, whereas RHB added to soil increased plant weight by increasing the stem size and leaf length of the water spinach. In addition, the stem size of water spinach was proportional to the $\mathrm{WHC} /$ silt ratio; whereas the root size of water spinach was proportional to the $\mathrm{OM} / \mathrm{OC}$ ratio of soil. We also proposed that the working mechanism of WB and RHB in soil would be such, that the decomposition of OC in biochar-added soil to OM resulted in increased WHC and decreased silt in biochar-added soil. The decomposition of WB biochar was faster than RHB under a lower dosage amount $\left(<1.5 \mathrm{~kg}^{\mathrm{m} 3}\right)$, but this trend was inversed with a higher dosage $\left(>3.0 \mathrm{~kg}^{\mathrm{m} 3}\right)$.
\end{abstract}

Keywords: soil fertility, biochar, water spinach, wood, soil amendments, rice husk 


\section{Introduction}

Rice husks, wood remains, nut shells, manure and crop residues are regarded as agricultural waste, but recently such solid wastes have been transformed into biochar for the purpose of carbon sequestration. Biochar is commonly defined as charred organic matter, produced with the intent of being deliberately added to soil to improve its agronomic properties. On average, one ton of dry biomass can create $400 \mathrm{~kg}$ of biochar containing 80 to $90 \%$ pure carbon (Lehmann et al., 2009) at 300 to $700{ }^{\circ} \mathrm{C}$, under low (preferably zero) oxygen concentrations. Rice husk contains a high content of silicon and potassium, nutrients which have great potential for amending soil, while those with a relatively higher carbon content (e.g. wood or nut shells) are currently used for the production of activated carbon.

The use of rice straw and rice husks in the field has been practiced for some time (Ponamperuma, 1982). Research has shown that incorporation of rice straw and rice husks can significantly improve soil properties by decreasing soil bulk density, enhancing soil $\mathrm{pH}$, adding organic carbon, increasing available nutrients and removing heavy metals from the system, ultimately increasing crop yields (Williams et al., 1972). Similar studies on cowpea, soybean, and maize (Yamato et al., 2006) have also supported the application of biochar as a way to increase crop yields. Asia, a principal rice growing region, has abundant rice residues, estimated at about 560 million tons of rice straw and 112 million tons of rice husks, respectively. These residues could be a valuable resource for the production of biochar to increase soil fertility.

Carbonized rice husks consist of a very light material with a micro-porous structure and a bulk density of about $0.150 \mathrm{~g} \mathrm{~cm}^{-3}$ (Haefele et al., 2009). The carbonization process also improves the waterholding capacity of the rice husks (Oshio et al., 1981). Additionally, the widespread old practice of burning rice straw in the field indicates that black carbon from incompletely burned (i.e. carbonized) rice residues could be an important source of organic matter in rice soils, as been previously shown for a range of other soil types (Schmidt and Noavk., 2000)

The effects of the addition of biochar may vary from soil to soil. However, the following effects have been seen in experiments: a) the rice husk charcoal increases the soil $\mathrm{pH}$, thereby increasing available phosphorus (P), b) improved aeration in the crop root zone, c) improved soil water - holding capacity and d) increased levels of exchangeable potassium $(\mathrm{K})$ and magnesium $(\mathrm{Mg})$ (FFTC, 2001). There is a need to highlight the agronomic properties and the effects of rice husks biochar on the growth of crops, to promote biochar use in the field by small landholders. With several Asian countries applying the carbonized rice residues, their real outcome has not been clarified. More field work is required to indicate the relationship between the amount of biochar applied and the growth rate of crops. Therefore, in this study, we examined the effects of rice husk biochar application and compared these results to wood biochar applied to increase the growth of water spinach (Ipomoea aquatica) in field conditions. Water spinach is a fast growing plant with strong system development. It originates from mainland China and is now widely grown worldwide. This study assumed that rice husk biochar could act as a soil conditioner, enhancing water spinach growth by supplying and retaining nutrients and thus improving the soil's physical and biological properties. Our aim was to explore whether rice husk biochar (RHB) and wood biochar (WB), in combination with fertilizers, could increase the biomass yield of water spinach. Soil analysis, shared use of a scanning electron microscope, and heavy metal analysis were used to identify the properties of rice husk biochar. We hope that the results of our work may help to determine which of the biochars is more beneficial in boosting the production of water spinach.

\section{Materials and Methods}

In a study made by Hossain et al., (2011) concerning the influence of pyrolysis temperature on production and the nutrient properties of biochar, researchers 
concluded that pyrolysis temperature has a significant effect on the chemical properties of the biochar produced. There are important implications regarding the suitability of biochar as a soil amendment. In this study, all biochars tested were produced at relatively low temperatures (250-300 oC) and were slightly alkaline.

\subsection{Biochar preparation and characterization}

Production of rice husk biochar (RHB) was carried out by the Industrial Technology Research Institute (ITRI), located in Hsinchu, Taiwan. RHB was pyrolysized using a small-scale reactor at $300-350^{\circ} \mathrm{C}$ with a residence time of 1 hour. These temperatures may be applicable for small scale farmers who lack access to credit and cannot afford high-scale pyrolysis plants. In order to observe the performance of both biochars in their original shapes, we avoided the use of grinders or sieves to reduce the particle size in the soil applications. Wood biochar (WB) was purchased in an agricultural shop near the experimental site and WB was prepared by open-burn (the proposed temperature was $250-300^{\circ} \mathrm{C}$ ).

Several analyses, including use of scanning electron microscopy (SEM) equipped with an energy dispersion X-ray spectroscopy (EDX), elemental analysis of biochars (EA), Fourier transform infrared spectroscopy (FT-IR), volatile matter (VM), surface area analysis (BET), electrical conductivity (EC), total dissolved solids (TDS) analysis, water-holding capacity (WHC), and heavy metal analysis (ICP), were used to characterize the properties of the biochars. By using an SEM S-3000N HITACHI production microscope, the morphology of both WB and RHB samples was examined. The sample powder was sprinkled as a thin layer on an adhesive tape placed on the brass sample holder. Excess amounts of the sample were removed with a small manual air blower. The adhered sample was then coated with gold powder using a sputtering device, the Ion Sputter E-1010 HITACHI, and then transferred into the JEOL sample chamber for analysis. The accelerating voltage was set at $15-40 \mathrm{kV} ; 200,300$ and 600 times magnification were selected. A Perkins-Elmer EA analyzer determined the elemental composition of the biochar, such as the biomass that would be ideal for application as biochar for carbon sequestration. A Bruker Vector-22 FT-IR spectrometer identified the sample to determine the organic functional groups present for each biomass, especially carbons. Volatile matter in biochar was determined following the ASTM D 3175 -07 standard test method. In order to determine the surface area of each biochar, samples were ground and sieved using a No. 60 mesh. A Beckman Coulter SA 3100 BET analyzer containing approximately $0.1000 \mathrm{~g}$ to $0.2000 \mathrm{~g}$ of each biochar sample was then used at a temperature of $50 \mathrm{C}^{\circ}$ for 60 min. Electrical conductivity and total dissolved solid analysis are theoretically the best measure of salinity to indicate the actual salinity level experienced by the plant root (Corwin and Lesch, 2003). Hence, electrical conductivity and total dissolved solids were measured using a SUNTEX SC-110 portable conductivity-meter. Samples were prepared at a ratio of 1:10 (sample: distilled water), mixed in a HMS212 stirrer for $30 \mathrm{~min}$, and then left to stand for 4 hours.

To evaluate the heavy metals present in the biochars, we used a leaching extraction procedure which follows the USA EPA method No.1311 with minor modifications; $5 \mathrm{~g}$ of ground and weighted biochar were added into a volumetric flask together with 1000 $\mathrm{ml}$ of distilled water and $5.7 \mathrm{~mL}$ of acetic acid. After samples were left for $18 \mathrm{~h}$ in a toxicity characteristics leaching procedure (TCLP) rotator, they were filtered and poured into $100 \mathrm{~mL}$ containers. The trace metals analysis in the samples was realized by using a PerkinElmer 3000-XL inductively coupled plasma (ICPAES) spectrometer.

\subsection{Field trial}

The experiment was carried out between December 2010 and February 2011 on the campus of National Pingtung University of Science and Technology 
$\left(22^{\circ} 38^{\prime} \mathrm{N}, 120^{\circ} 36^{\prime} \mathrm{E}\right)$ in Pingtung County in the southern part of Taiwan. The climate in this area is humid and tropical with predominantly summer rainfall. The rainy season from May to September accounts for $90 \%$ of the annual precipitation with the remainder falling between October and April. With an annual average of $24^{\circ} \mathrm{C}$, the temperature ranges from $10^{\circ} \mathrm{C}$ during the coldest months, January to March, to $38^{\circ} \mathrm{C}$ in the hottest months, June to August.

Water spinach plants were germinated for two weeks and later transplanted into plots. Each plot was $1.94 \mathrm{~m}$ $\mathrm{x} 1.10 \mathrm{~m}$. Five different treatments were assigned to each of the biochars and to one control group. RHB and WB were weighted and added to each plot. Every plot was mixed with the assigned quantity of biochar using a top soil mixing technique (Major, 2009). Before transplanting, each plot was irrigated for 20 min. Plants were transplanted $15 \mathrm{~cm}$ apart, with 22 plants per plot. A perforated pipe system was used to water the plants every 2 days for $10 \mathrm{~min}$. Soluble N-P-K fertilizer 20-20-20 was applied to the crops; $1 \mathrm{~g}$ of the fertilizer was dissolved in 2 liters of water and the procedure was repeated for each of the plots. The application was made only ONE time during the growth of the plants during the second week. After eight weeks of growth, the plants were harvested Plant morphological characteristics measured included: leaf number, leaf length, leaf width, stem number, stem size, fresh plant weight, root growth and the chlorophyll content of the leaves. The effect of biochar on root growth was measured to compare the effects of the different types and quantities of rice husk and wood biochars used. Ten water spinach plants were randomly selected from each treatment; their roots were washed to avoid loose soil and blotted to remove any free surface moisture. After plants were harvested and their roots measured, each was weighed; plants were collected and grouped by treatment in order to obtain their total fresh weight. Relative chlorophyll content (Soil Plant Analysis Development (SPAD)) was measured every two days using a Minolta chlorophyll meter (model SPAD 502).

\subsection{Soil analysis}

Soil was sampled from a 0 to $20 \mathrm{~cm}$ horizon on a clayey Ultisol, which is typically used for vegetable and fruit production in southern Taiwan. There were eleven treatments for rice husk biochar and wood biochar, along with one control group. Four soil samples from each treatment were dried in a precision oven at $35^{\circ} \mathrm{C}$, homogenously mixed, ground and passed through a $2 \mathrm{~mm}$ sieve. A 20:20 (soil: distilled water) solution ration was prepared for the determination of $\mathrm{pH}$. Organic carbon $(\mathrm{OC})$ and organic matter $(\mathrm{OM})$ were determined using the Walkley-Black method (Walkley and Black, 1934). Soil texture and characteristics were also obtained using the hydrometer method (Milford, 1997).

The water-holding capacity (WHC) of biochars was measured, following procedures for soil analysis as outlined in a manual (Lee, 2007). Soil samples where oven dried for $24 \mathrm{~h}$ at $105^{\circ} \mathrm{C}$; then $5 \mathrm{~g}$ of each sample were poured into a $100 \mathrm{~mL}$ beaker and distilled water was added until the saturation point was reached and the weight loss could be counted for the water-holding capacity of the sample. ANOVA was implemented using the SAS GML procedure. Both biochar treatments were compared using least significant differences at the significance level of $\mathrm{P}<0.05$ to determine the main effect of both biochars on plant growth properties.

\section{Results and Discussion}

\subsection{Characteristics of biochar}

The SEM-EDX analysis showed that the microstructure of the rice husk biochar was highly heterogeneous. Rice husk biochar particles consisted of higher silicon (Si) mineral agglomerates on lower carbon content fibers with structures typical of its biomass origin. They exhibited a large degree of macro-porosity in the 1 to 10 micron scale, with contents of carbon (C), oxygen (O) and potassium (K). On the other hand, SEM-EDX analysis for WB indicated that the biochar particles 
consisted of high potassium, chlorine $(\mathrm{Cl})$ and calcium mineral agglomerates. This analisys further demonstrates high carbon content and a large degree of macro-porosity in the 1 to 10 micron scale, with contents of Potassium $(\mathrm{K})$, Carbon $(\mathrm{C})$, Chlorine $(\mathrm{Cl})$ and Calcium $(\mathrm{Ca})$.

The results of FT-IR and elemental analysis showed that rice husk biochar has relatively higher complexation ability on the surface than does wood biochar. Results from several analyses, including: EA, BET surface area, EC, TDS, and ICP heavy metal analysis, revealed the applicability of rice husk and wood biochars on soil. Table 1 shows a list of important elements contained in biochar that could be beneficially incorporated into soils. Results from EA tests show a high percentage of carbon in wood biochar. According Stoylle (2011), a high percentage of carbon means the biochar can absorb more atmospheric $\mathrm{C}$ from the environment. Rice husk had a higher VM content as compared to rice husk and wood biochars. In comparison with rice husk, wood exhibits a larger BET surface area $/ \mathrm{m}^{2}$. Rice husk biochar has a significantly higher EC value than wood biochar, meaning greater quantities of dissolvable ions are present in rice husk biochar than in wood (Basile-Doelsch et al., 2007).

Concentrations of heavy metals in the tested biochars were all far below the ICP detection limits. Major differences between wood and rice biochar were in the content of $\mathrm{Na}$ and Mn. RHB had slightly alkaline properties with a $\mathrm{pH}$ of 8.02; this was relatively higher than wood biochar due to the high ash content. The former also had higher elemental $\mathrm{Si}$ and $\mathrm{Mg}$ but a lower content of Ca compared to the wood biochar. In addition, characterization of biochar showed contents of potassium $(\mathrm{K})$, and a high concentration of silicon ( $\mathrm{Si}$ ). Silicon ( $\mathrm{Si}$ ) is not yet classed as an essential nutrient but it exists in all plants grown in soil, and is recognized as a functional nutrient. Benefits of silicon include: increased pest and pathogen resistance, drought and heavy metal tolerance, and improved quality and yield of agricultural crops. Si is taken up at levels equal to or greater than levels of essential nutrients such as Nitrogen and Potassium in certain plants such as rice and sugarcane. As a result, it is considered agronomically essential for sustainable crop production (Savant et al.,
1999). Si nutrition plays an important role in the water spinach nutrition. The nutrient condition of the Ultisol was increased and it boosted mass production of the plant, showing differences when compared with the mass production of water spinach where wood biochar was applied. Rice husks are unique. They contain approximately $20 \%$ opaline silica in combination with a large amount of the phenyl propanoid structural polymer called lignin.

\subsection{Effect of biochar application in soil properties}

A review by Glaser et al., (2002) suggested that biochar added to soils may not only change its chemical properties but also affect physical properties such as soil water-holding and aggregation. These effects may enhance water availability to crops and decrease erosion. Results in Table 2 indicate that the addition of both biochars to soil did not drastically affect the $\mathrm{pH}$ of testing soil. In addition, the OC content was increased with the addition of rice husk and wood biochar, with the highest content shown in wood biochar (WB-2). The percentage of OM was not much affected after the biochar addition, as compared to CT. In our study, the water-holding capacity (WHC) increased to a maximum value and then decreased as the application of biochar was increased. The highest ratio of RHB biochar had the same WHC within the CT and FS groups. Soil from the NPUST campus field was found to be medium acidic with a $\mathrm{pH}$ between 5.02 and 6.69 (classified as very strong acid-medium acid soil). Chan et al., (2007) showed that biochar application improved some physical soil properties, such as: increased soil aggregation, water holding capacity and decreased soil strength. Rice husk alone has a percentage water-holding capacity of 251 that is enhanced by the carbonization process, resulting in up to $353 \%$ water retention in rice husk biochar. RHB could decrease moisture retention in clayey soils. Increased moisture retention and water bioavailability is thought to be a critical factor in achieving greater yields with biochar amended fields. Generally, water retention is increased as the amount of organic matter in achieving greater yields with biochar amended fields. 
Table 1. Properties of fresh rice husk biochar and wood biochar used in this experiment

\begin{tabular}{|c|c|c|c|}
\hline $\begin{array}{l}\text { Elements } \\
\text { evaluated }\end{array}$ & $\begin{array}{l}\text { Fresh rice } \\
\text { husk }\end{array}$ & $\begin{array}{l}\text { Rice husk } \\
\text { biochar }\end{array}$ & $\begin{array}{l}\text { Wood } \\
\text { biochar }\end{array}$ \\
\hline $\mathrm{T}\left({ }^{0} \mathrm{C}\right)$ & - & $300-350$ & - \\
\hline $\mathrm{Si}(\mathrm{mg} / \mathrm{kg})$ & 107 & 171 & 10 \\
\hline $\mathrm{Ca}(\mathrm{mg} / \mathrm{kg})$ & 108 & 220 & 273 \\
\hline $\mathrm{K}(\mathrm{mg} / \mathrm{kg})$ & 9523 & 175 & 305 \\
\hline $\mathrm{Mg}(\mathrm{mg} / \mathrm{kg})$ & 175 & 182 & 72.23 \\
\hline Water (\%) & 11.3 & 3.9 & - \\
\hline Ash (\%) & 12.63 & 50.53 & - \\
\hline pH (\%) & 6.41 & 8.02 & 7.32 \\
\hline Fixed C (mg) & - & 43.73 & 52.74 \\
\hline $\mathrm{H}(\mathrm{mg})$ & - & 2.38 & 3.58 \\
\hline N (mg) & - & 1.0 & 0.72 \\
\hline S (mg) & - & 0.19 & 0.37 \\
\hline O (mg) & - & 2.36 & - \\
\hline Volatile & 2.42 & 1.86 & 1.70 \\
\hline \multicolumn{4}{|l|}{ Matter (\%) } \\
\hline \multicolumn{4}{|l|}{ Analysis $\left(\mathrm{m}^{2}\right)$} \\
\hline $\mathrm{EC}(\mu \mathrm{s} / \mathrm{cm})$ & 1220 & 1392 & 704 \\
\hline TDS (ppm) & 488 & 558 & 282 \\
\hline Sal (ppt) & 0.2 & 0.2 & 0.1 \\
\hline $\mathrm{Fe}(\mathrm{mg} / \mathrm{L})$ & - & 8.72 & 0.1 \\
\hline $\mathrm{Al}(\mathrm{mg} / \mathrm{L})$ & - & 0.97 & 0.37 \\
\hline $\mathrm{Cu}(\mathrm{mg} / \mathrm{L})$ & - & 0.09 & 0.01 \\
\hline $\mathrm{Pb}(\mathrm{mg} / \mathrm{L})$ & - & - & - \\
\hline $\mathrm{Zn}(\mathrm{mg} / \mathrm{L})$ & - & 0.7 & 0.4 \\
\hline Cd (mg/L) & - & - & - \\
\hline $\mathrm{Ni}(\mathrm{mg} / \mathrm{L})$ & - & 0.11 & - \\
\hline $\mathrm{Cr}(\mathrm{mg} / \mathrm{L})$ & - & 0.03 & - \\
\hline $\mathrm{Na}(\mathrm{mg} / \mathrm{L})$ & - & 7.49 & 23.9 \\
\hline $\mathrm{Sb}(\mathrm{mg} / \mathrm{L})$ & - & - & - \\
\hline $\mathrm{Mn}(\mathrm{mg} / \mathrm{L})$ & - & 5.27 & 3.6 \\
\hline Sn (mg/L) & - & - & - \\
\hline $\mathrm{Sr}(\mathrm{mg} / \mathrm{L})$ & - & 0.07 & 1.22 \\
\hline
\end{tabular}

Pyrolysis temperature of wood biochar was not determined due to its unknown origin. Oxygen content was calculated: $\mathrm{O}=100-(\mathrm{C}+\mathrm{H}+\mathrm{N}+\mathrm{Ash})$. TDS and salt are directly proportional to EC 
Table 2. Effect of biochar in some soil properties

\begin{tabular}{lccccccccc}
\hline & Biochar & $\mathrm{pH}$ & OC & OM & WHC & Clay & Silt & Sand & Texture \\
& & & & & & & & & \\
Treatment & \multirow{2}{*}{$\left(\mathrm{kg} / \mathrm{m}^{3}\right)$} & & & & & & & \\
No. & & & & & & & & & \\
\hline RHB-1 & 4.0 & 6.66 & 1.43 & 2.46 & 58.53 & 6 & 60 & 34 & Silt loam \\
RHB-2 & 3.0 & 6.62 & 1.44 & 2.49 & 61.56 & 6 & 59 & 35 & Silt loam \\
RHB-3 & 2.0 & 5.26 & 1.59 & 2.74 & 73.65 & 7 & 72 & 21 & Silt loam \\
RHB-4 & 1.0 & 5.02 & 1.46 & 2.51 & 70.26 & 8 & 74 & 18 & Silt loam \\
RHB-5 & 0.5 & 6.61 & 0.87 & 1.54 & 61.84 & 9 & 73 & 19 & Silt loam \\
& & & & & & & & & \\
WB-1 & 4.0 & 6.67 & 1.24 & 2.14 & 68.23 & 6 & 63 & 31 & Silt loam \\
WB-2 & 3.0 & 5.4 & 2.15 & 3.71 & 54.23 & 6 & 66 & 28 & Silt loam \\
WB-3 & 2.0 & 5.13 & 1.47 & 2.54 & 64.38 & 7 & 67 & 26 & Silt loam \\
WB-4 & 1.0 & 6.62 & 1.08 & 1.87 & 61.00 & 6 & 61 & 33 & Silt loam \\
WB-5 & 0.5 & 6.65 & 1.53 & 2.64 & 56.72 & 7 & 69 & 25 & Silt loam \\
CT & - & 6.64 & 1.49 & 2.56 & 57.82 & 5 & 58 & 36 & Silt loam \\
FS & - & 6.69 & 0.77 & 1.33 & 56.96 & 7 & 72 & 21 & Silt loam \\
\hline
\end{tabular}

$\mathrm{RHB}=$ Rice husk biochar, $\mathrm{WB}=$ Wood biochar, $\mathrm{CT}=$ Control treatment, $\mathrm{FS}=$ Field soil

Generally, water retention is increased as the amount of organic matter in soil is increased. Sohi et al., (2009), hypothesized that the addition of biochar to soils may lead to increased levels of organic content. This may partially explain improved water retention, while Glaser et al., (2002), found that Terra Preta soils rich in charcoal had an $18 \%$ greater water retention than did neighboring soils that did not contain significant charcoal deposits. In this study little increase in WHC was observed. The WHC of soil containing applied biochar was found to increase by only about $10 \%$.

\subsection{Effect of biochar in plant morphology}

Results from this study reveal that the response of water spinach to biochar application varied between biochar types. The addition of fertilizer and biochar gives a positive outcome in terms of plant growth. A greater increase in biomass production was observed with the application of fertilizer and rice husk biochar to the Ultisoil soil. Little response in the CT group without fertilizer was observed. Ultisols is acidic in nature and is considerably productive under good management (Brady and Weil, 1999). However, high acidity and relatively low availability of calcium, magnesium and potassium make these soils poorly suited for continuous agriculture without the addition of fertilizer and lime. RHB is shown to provide special benefits to Ultisol soils, resulting in improved biomass production. Plants grown with $1.0 \mathrm{~kg}$ (RHB-4) had the maximum average leaf number. 
Table 3. The effects of biochar type on water spinach growth parameters

\begin{tabular}{lllllllll}
\hline Treatments & $\begin{array}{l}\text { Biochar } \\
\text { quantity } \\
\left(\mathrm{kg} / \mathrm{m}_{3}\right)\end{array}$ & $\begin{array}{l}\text { Leaf } \\
\text { number }\end{array}$ & $\begin{array}{l}\text { Leaf wide } \\
(\mathrm{mm})\end{array}$ & $\begin{array}{l}\text { Leaf } \\
\text { Length } \\
(\mathrm{mm})\end{array}$ & $\begin{array}{l}\text { Stem } \\
\text { number }\end{array}$ & $\begin{array}{l}\text { Stem Size } \\
(\mathrm{mm})\end{array}$ & $\begin{array}{l}\text { Root size } \\
(\mathrm{mm})\end{array}$ & $\begin{array}{c}\text { Plant } \\
\text { Weight } \\
(\mathrm{g})\end{array}$ \\
\hline RHB-1 & 4.0 & $29.90 \mathrm{cb}$ & $22.45 \mathrm{a}$ & $150.27 \mathrm{a}$ & $3.00 \mathrm{ab}$ & $189.09 \mathrm{ab}$ & $157.45 \mathrm{ab}$ & 545.50 \\
RHB-2 & 3.0 & $25.50 \mathrm{~cd}$ & $22.95 \mathrm{a}$ & $143.50 \mathrm{a}$ & $3.00 \mathrm{ab}$ & $189.45 \mathrm{ab}$ & $157.14 \mathrm{ab}$ & 540.00 \\
RHB-3 & 2.0 & $35.27 \mathrm{ab}$ & $17.81 \mathrm{~b}$ & $135.90 \mathrm{a}$ & $3.31 \mathrm{a}$ & $168.64 \mathrm{~b}$ & $134.09 \mathrm{c}$ & 505.00 \\
RHB-4 & 1.0 & $40.81 \mathrm{a}$ & $20.63 \mathrm{ab}$ & $142.59 \mathrm{a}$ & $3.22 \mathrm{ab}$ & $213.50 \mathrm{a}$ & $177.41 \mathrm{a}$ & 617.50 \\
RHB-5 & 0.5 & $37.77 \mathrm{ab}$ & $20.18 \mathrm{ab}$ & $137.22 \mathrm{a}$ & $2.86 \mathrm{ab}$ & $194.45 \mathrm{ab}$ & $172.32 \mathrm{a}$ & 472.50 \\
CT & 0.0 & $20.90 \mathrm{~d}$ & $13.13 \mathrm{c}$ & $104.86 \mathrm{~b}$ & $2.77 \mathrm{~b}$ & $130.95 \mathrm{c}$ & $141.09 \mathrm{bc}$ & 217.50 \\
Mean RHB & & $31.69 \mathrm{a}$ & $135.72 \mathrm{a}$ & $19.53 \mathrm{a}$ & $3.03 \mathrm{a}$ & $181.01 \mathrm{a}$ & $156.58 \mathrm{a}$ & 483.00 \\
WB-1 & 4.0 & $22.81 \mathrm{~b}$ & $10.31 \mathrm{~b}$ & $82.77 \mathrm{c}$ & $2.45 \mathrm{a}$ & $106.41 \mathrm{c}$ & $114.09 \mathrm{~b}$ & 170.00 \\
WB-2 & 3.0 & $30.18 \mathrm{a}$ & $15.04 \mathrm{a}$ & $115.95 \mathrm{a}$ & $2.86 \mathrm{a}$ & $170.68 \mathrm{a}$ & $133.41 \mathrm{ab}$ & 325.00 \\
WB-3 & 2.0 & $23.86 \mathrm{~b}$ & $14.04 \mathrm{a}$ & $93.77 \mathrm{bc}$ & $2.77 \mathrm{a}$ & $140.45 \mathrm{~b}$ & $133.64 \mathrm{ab}$ & 210.00 \\
WB-4 & 1.0 & $22.04 \mathrm{~b}$ & $9.59 \mathrm{~b}$ & $90.40 \mathrm{bc}$ & $2.40 \mathrm{a}$ & $132.27 \mathrm{bc}$ & $114.77 \mathrm{~b}$ & 125.00 \\
WB-5 & 0.5 & $23.45 \mathrm{~b}$ & $14.95 \mathrm{a}$ & $103.54 \mathrm{ab}$ & $2.77 \mathrm{a}$ & $153.55 \mathrm{ab}$ & $137.55 \mathrm{ab}$ & 245.00 \\
CT & 0.0 & $20.90 \mathrm{~b}$ & $13.13 \mathrm{ab}$ & $104.86 \mathrm{ab}$ & $2.77 \mathrm{a}$ & $130.95 \mathrm{bc}$ & $141.09 \mathrm{a}$ & 217.50 \\
Mean WB & & $23.87 \mathrm{~b}$ & $98.55 \mathrm{~b}$ & $12.84 \mathrm{~b}$ & $2.67 \mathrm{~b}$ & $139.05 \mathrm{~b}$ & $129.09 \mathrm{~b}$ & 215.42 \\
\hline
\end{tabular}

$\mathrm{RHB}=$ Rice husk biochar, $\mathrm{WB}=$ Wood biochar, $\mathrm{CT}=$ Control treatment, $\mathrm{FS}=$ Field soil

a, b. Means with the same letter are not significantly different at 5\% level, according to Fisher LSD test.

A combination of biochar with fertilizer showed a significant effect in increasing leaf width in all plants. No observable difference resulted from treatments when 4.0 $\mathrm{kg}$ (RHB-1) and $3.0 \mathrm{~kg}$ (RHB-2) were added. Differences in leaf length were found only with the control group, whereas the RHB-3 and RHB-4 treatments, showed higher values for stem number and size, respectively.

\subsection{Effect of biochar on plant growth}

Table 3 shows the comparative effects of biochar on plant growth parameters, such as leaf number, leaf width, leaf length, stem number, stem size, root size and fresh plant weight. RHB-4 treatment $(1.0 \mathrm{~kg})$ showed the highest number of leaves and larger stem size (40.81 and 215.50 mm respectively). RHB-2 (3.0 kg) and RHB-3 (2.0 kg) treatments resulted in a higher mean leaf width. For leaf length, all treatments with rich husk biochar resulted in significantly higher $(p<0.05)$ values than were observed in the control group. Regarding the number of stems, both RHB-3 and RHB-4 treatments showed good performance. Treatment RHB-4 also had the best effect on fresh plant weight $(617.5 \mathrm{~g})$. Compared with rice husk biochar, however, wood biochar appeared to be less effective in affecting the growth of water spinach, particularly in terms 
of fresh plant weight. Increments between plants grown in rice husk and wood biochars were $124.6 \%$ for biomass production, $52.1 \%$ for leaf width, $37.7 \%$ for leaf length, $32.76 \%$ for leaf number, $30.17 \%$ for stem size, $21.3 \%$ for root size and $13.4 \%$ for stem number.

According to the Least Significant Difference test, the rice husk biochar treatment showed a significantly higher effect on biomass growth than did wood biochar according to every parameter measured. The results suggest that the efficiency of RHB is higher than that of WB.

\subsection{Effect of biochar on chlorophyll content}

Leaf chlorophyll content for each group treated was measured for 8 weeks ( 40 days approximately) during the experiment. Between day 1 and 17, a considerable increase in chlorophyll content was observed, while the levels of chlorophyll tended to gradually decrease during the remaining days. This result may be related to differences in daily chlorophyll collection times and the stage of plant growth which varied among the plant groups being treated. Noticeably, RHB-3 treatment containing $2.0 \mathrm{~kg}$ of rice husk biochar, achieved the highest value (47.15) of chlorophyll level. No significant differences were found between treatments for the WB-2, WB-5 and the control group. It can be noted that application of wood biochar resulted in only a minimal difference in chlorophyll content as compared to rice husk biochar treated plants, and had no significant differences with the CT group.

The addition of RHB to an Ultisols soil showed better results than those supplemented with wood biochar, not only in terms of the chlorophyll content of leaves but also in biomass production. It is widely known that leaf chlorophyll content is an important parameter for testing plant status. For example, chlorophyll content can be used as an index of photosynthetic potential as well as an index of plant productivity (Carter, 1998). In addition, chlorophyll gives an indirect estimation of the nutrient status since much of the leaf nitrogen is incorporated within the chlorophyll. Furthermore, leaf chlorophyll content is closely related to various types of plant stresses and senescence (Carter et al., 1996). In recent years, chlorophylls, the most abundant pigments in green plants, have been gaining increasing recognition as an essential part of the human diet, not only as food colorants, but also as healthy food ingredients. Chlorophyll content or leaf greenness is affected by a number of factors, one being the $\mathrm{N}$ status of the plant (Peterson et al., 2010).

\subsection{Effect of Si content in rice husk biochar.}

Silicon oxide forms the main component (90-97\%) of the rice husk ash with trace amounts of $\mathrm{CaO}, \mathrm{MgO}, \mathrm{K}_{2} \mathrm{O}$ and $\mathrm{Na}_{2} \mathrm{O}$. The melting point of $\mathrm{SiO}_{2}$ is $1410-1610^{\circ} \mathrm{C}$, while those of $\mathrm{K}_{2} \mathrm{O}$ and $\mathrm{Na}_{2} \mathrm{O}$ are $350^{\circ} \mathrm{C}$ and $1275^{\circ} \mathrm{C}$, respectively. It has been suggested that at higher temperatures, the low-melting oxides fuse with silica on the surface of the rice husk char and form glassy or amorphous phases, preventing the completion of a reaction (Bharadwaj et al., 2004). An analysis of the fresh rice husks (CT) used in this test to obtain biochar showed high levels of $\mathrm{Si}, \mathrm{Ca}$ and $\mathrm{Mg}$ (Table 1). After the pyrolysis process, the same elements were found to increase in the rice husk biochar. WB was found to have a higher content of $\mathrm{K}$ and surface area when compared with RHB, but had a lower content of Si and ash content (Table 1 and Figure 1).

\subsection{Effect of soil structure on the plant physiology of water spinach growth.}

In terms of crop production, the application of biochar should be beneficial to the plant weight of landscape-grown plants, but we cannot derive further new information from Figure 1. As indicated in Figure 2a, the WB added soil increased the plant weight of water spinach by increasing the root size and leaf width; while the RHB added soil increased the plant weight of water spinach by increasing the stem size and leaf length, as seen in Figure 2b. In Figure $3 \mathrm{a}$, the stem size of water spinach is shown to be proportional to the $\mathrm{WHC} /$ silt ratio, while the root size of water spinach is proportional to the $\mathrm{OM} / \mathrm{OC}$ ratio, as shown in Figure $3 \mathrm{~b}$. 


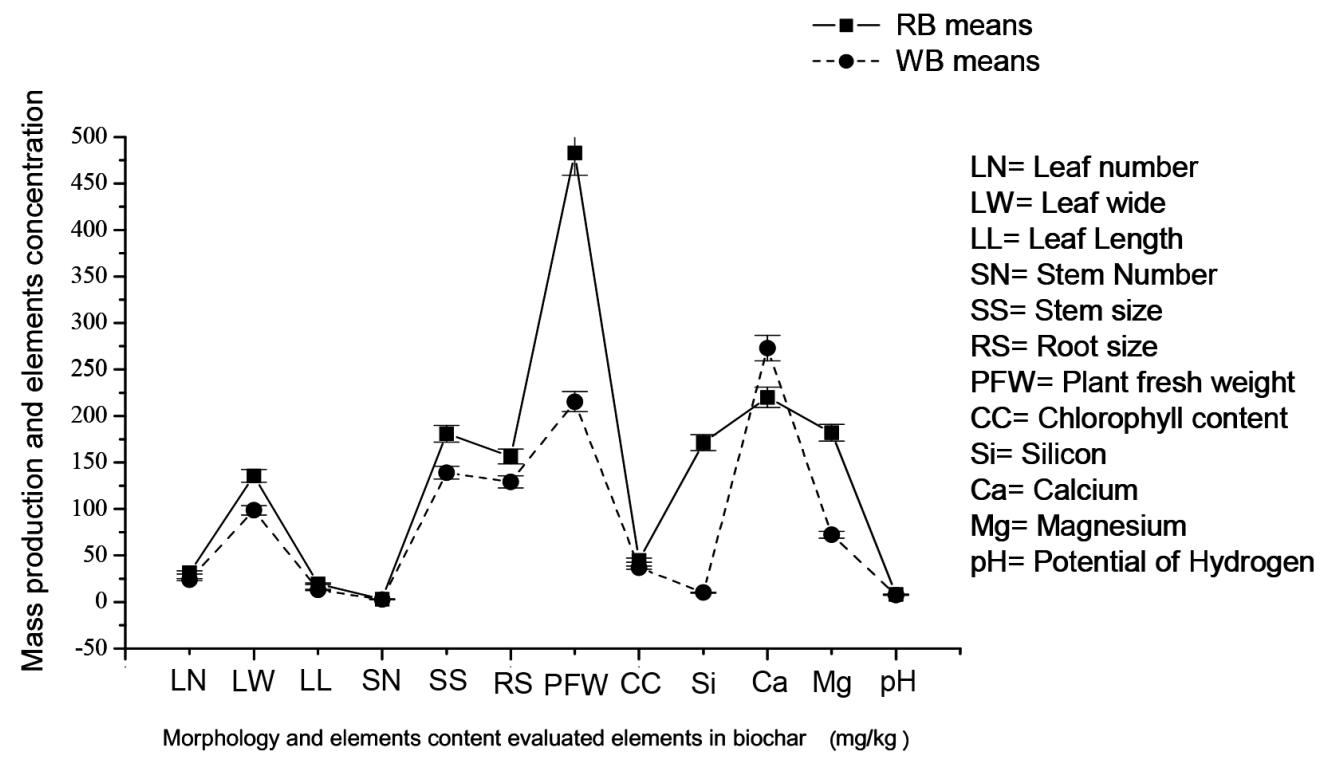

Figure 1. Differences in morphology evaluated in water spinach, where rice husk biochar and wood biochar was applied and beneficial elements present in tested materials

(a)

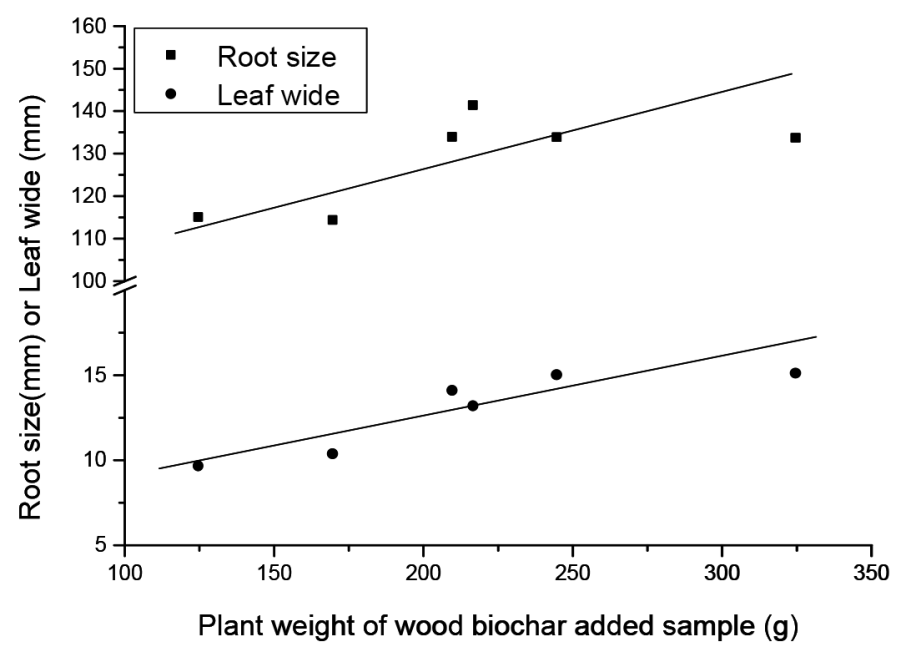

Figure 2a. The relations between root size and leaf wide and plant weight of WB 
(b)

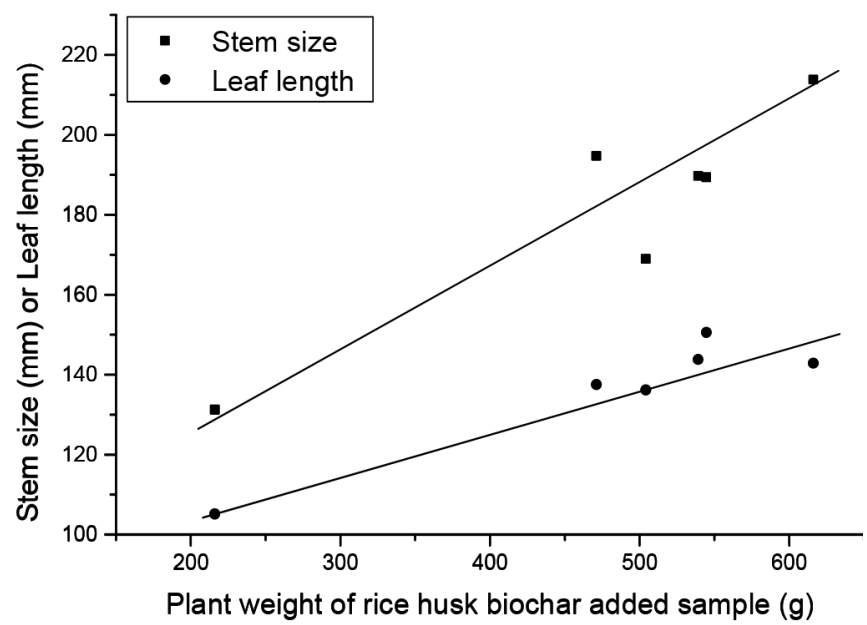

Figure 2b. Relations between stem size and leaf length and plant weight of RHB added plant samples.

(a)

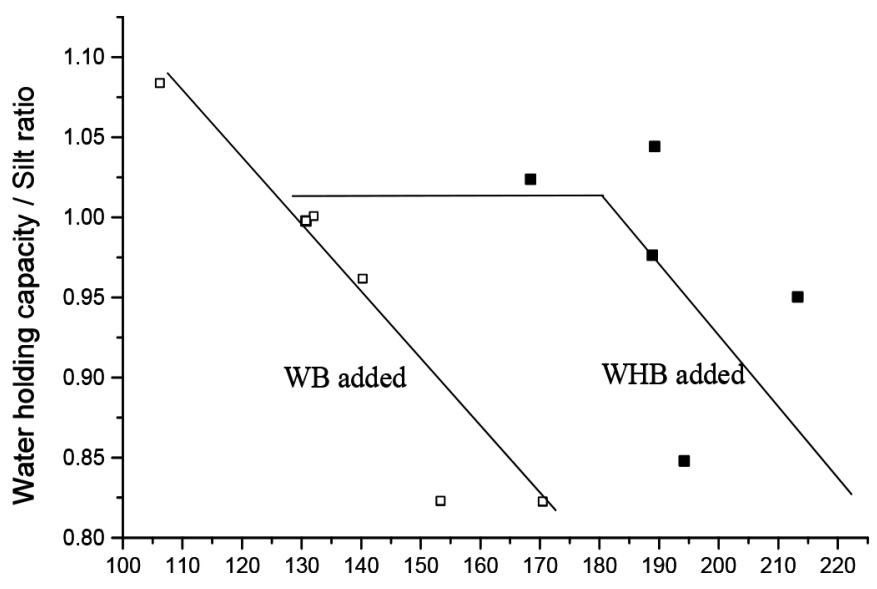

Stem size of wood biochar and rice husk biochar added sample $(\mathrm{mm})$

Figure 3a. The relations between and WHC/silt ratio and stem size of RHB and WB added plant samples 
(b)

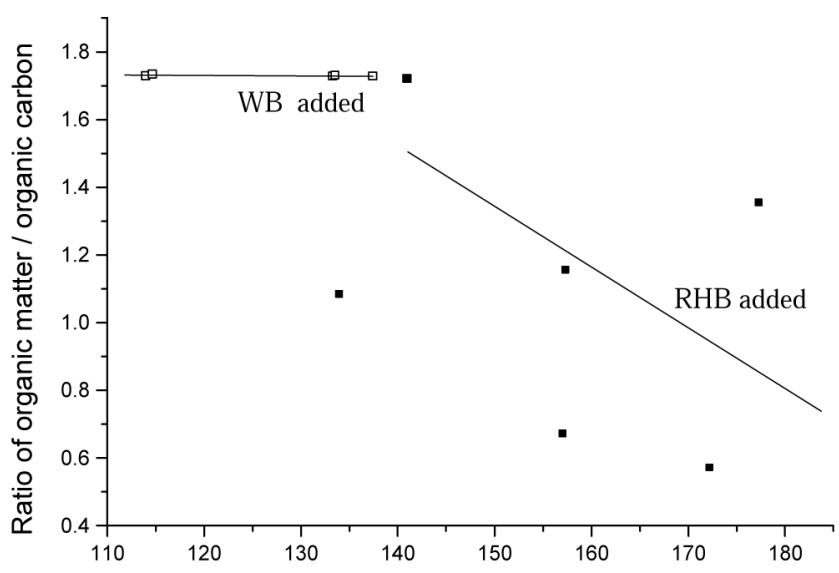

Root Size of wood biochar and rice husk biochar added sample $(\mathrm{mm})$

Figure 3b. relations between and $\mathrm{OM} / \mathrm{OC}$ ratio and root size of RHB and WB added plant samples.

(a)

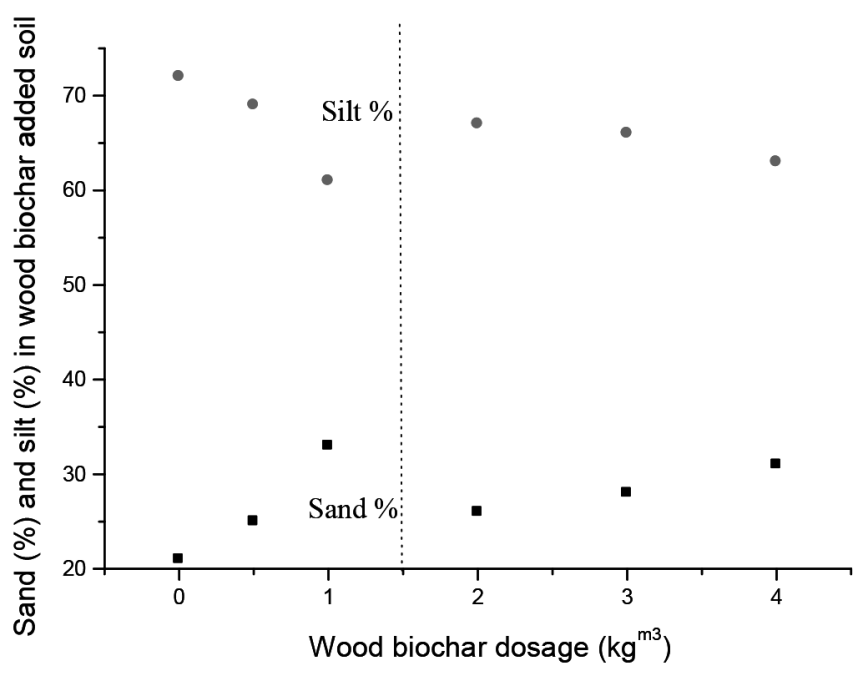

Figure 4a. Changes of sand and silt content in the WB added soil 


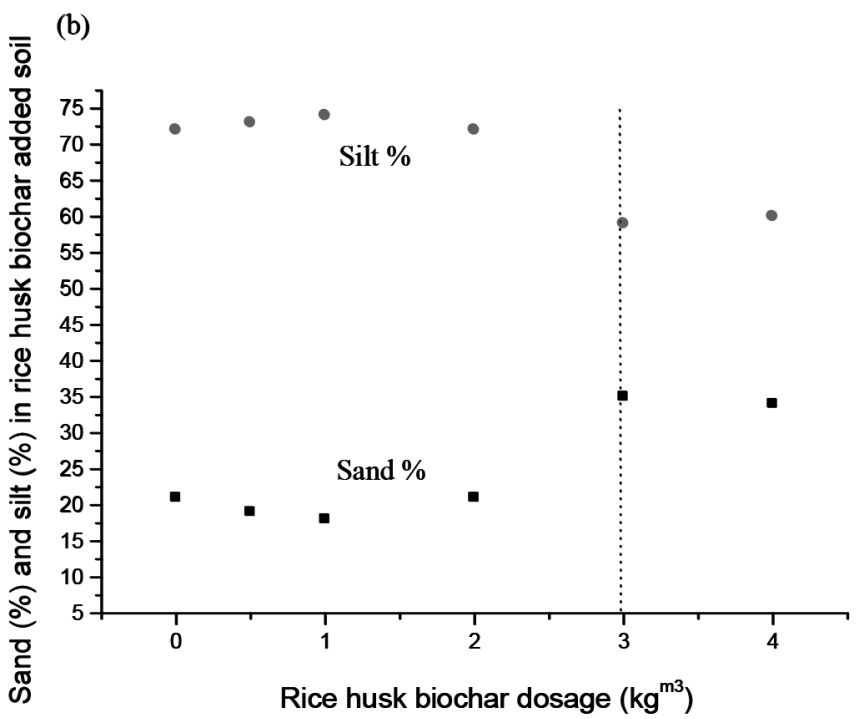

Figure 4b, changes of sand and silt content in the RHB added soil.

Table 4. The LSD test of biochar effect on plant growth parameters

\begin{tabular}{|c|c|c|c|c|c|c|c|}
\hline Biochar type & $\begin{array}{l}\text { Leaf number } \\
\text { (mean) }\end{array}$ & $\begin{array}{l}\text { Leaf } \\
\text { width } \\
\text { (mean) }\end{array}$ & $\begin{array}{l}\text { Leaf } \\
\text { length } \\
\text { (mean) }\end{array}$ & $\begin{array}{l}\text { Stem } \\
\text { number } \\
\text { (mean) }\end{array}$ & $\begin{array}{l}\text { Stem } \\
\text { size } \\
\text { (mean) }\end{array}$ & $\begin{array}{l}\text { Root } \\
\text { size } \\
\text { (mean) }\end{array}$ & $\begin{array}{l}\text { Plant weight } \\
\text { (Biomass production) } \\
\text { (mean) }\end{array}$ \\
\hline RHB & $31.69 \mathrm{a}$ & $19.53 \mathrm{a}$ & $135.72 \mathrm{a}$ & $3.03 \mathrm{a}$ & $181.01 \mathrm{a}$ & $156.58 \mathrm{a}$ & 483 a \\
\hline WB & $23.87 \mathrm{~b}$ & $12.84 \mathrm{~b}$ & $98.55 \mathrm{~b}$ & $2.67 \mathrm{~b}$ & $139.05 \mathrm{~b}$ & $129.09 \mathrm{~b}$ & $215.41 \mathrm{~b}$ \\
\hline CT & 20.9 & 13.13 & 104.86 & 2.77 & 130.95 & 141.09 & 217 \\
\hline
\end{tabular}

RHB $=$ Rice husk biochar, $\mathrm{WB}=$ Wood biochar, $\mathrm{CT}=$ Control treatment, $\mathrm{FS}=$ Field soil

a, b: Means with the same letter are not significantly different at $5 \%$ level, according to Fisher LSD test. 
The existing literature (Haefele et al., 2011; Rawat et al., 2010) has also illustrated that the soil OM increases the WHC of sandy loam while increasing aeration in silt and clay loam. It also indicates the releasing of OC and NPK to soil OM through decomposition reaction. In this study, changes in the silt and sand content in the test soils described in Table 2 and Figure $4 \mathrm{a}$ and $4 \mathrm{~b}$ have been found; we can conclude that the decomposition of $\mathrm{OC}$ in biochar to soil $\mathrm{OM}$ resulting in the increase in WHC and the decreasing in silt is the mechanism of WB and RHB application in this study. Based on the study of Lehmann (Kimetu and Lehmann, 2010), the stability of biochar is affected by pre-existing soil $\mathrm{OM}$; therefore, the results of $4 \mathrm{a}$ and $4 \mathrm{~b}$ illustrate that the decomposition reaction of WB biochar is faster than that of RHB under a lower dosage amount $(<1.5$ $\left.\mathrm{kg}^{\mathrm{m} 3}\right)$, while this reaction is inversed with an increased dosage $\left(>3.0 \mathrm{~kg}^{\mathrm{m} 3}\right)$. The $\mathrm{Si}$ and ash content are much richer in RHB than in WB, while $\mathrm{K}$ and surface area content is much higher in WB than in RHB. Although the detailed effects of $\mathrm{Si}$, ash, $\mathrm{K}$ and surface area on soil structure have not been well studied, we believe that these four chemical properties of WB and RHB biochars actually change the soil structure and also provide a proper fertilizing capacity for the test plant.

\section{Conclusions}

Rice husks and non-valuable wood are regarded as an agriculture waste product, but recently people have used such solid wastes to sequester carbon by processing them into biochar. This study compared the agronomic properties of rice husk and wood biochar, and investigated their effects on the growth rate of water spinach. The field testing results with water spinach showed that the application of rice husk biochar improves biomass production. The wood biochar added soil increased the plant weight of water spinach by increasing the root size and leaf width; while the rice husk biochar supplemented soil increased the plant weight of water spinach by increasing the stem size and lead length. In addition, the stem size of water spinach is proportional to the water holding capacity/ silt ratio, while the root size of water spinach is proportional to organic matter/organic carbon ratio of soil. We also propose that the working mechanism of wood biochar and rice husk biochar in soil would be such that the decomposition of organic carbon in biochar to soil organic matter resulted in the increased water holding capacity and decreased silt of biocharadded soil. The decomposition reaction of wood biochar is faster than that of rice husk biochar under a lower dosage amount $\left(<1.5 \mathrm{~kg}^{\mathrm{m} 3}\right)$ whereas this process is inversed when the dosage is increased $\left(>3.0 \mathrm{~kg}^{\mathrm{m} 3}\right)$.

\section{Acknowledgments}

The authors would like to acknowledge the Industrial Technology Research Institute for financing this research. Also would like to acknowledge Ms. R. Y. Chang for the ICP and EA operational help.

\section{References}

Basile-Doelsch, I., Amudson, R., Stone, W.E.E., Borschneck, D., Bottero, J.Y., Moustier, T., Masin ,F., Colin, F. 2007. Mineral control of carbon pools in a colcanic horizon. Geoderma. 137, 437-489.

Bharadwaj, A., Wang, Y., Sridhar, S., Arunachalam, V.S. 2004. Pyrolysis of rice husk. Center for Energy and Environment Studies and Department of Material Science and Engineering, Carnegie Mellon University, Pittsburgh, USA. Curr. Sci. India. 87, pp. 982.

Brady, N.C., Weil, R.R. 1999. The Nature and Properties of Soils: twelfth edition. Upper Saddle River, NJ: Prentice Hall.

Carter, G.A., Cibula, W.G., Miller, R.L . 1996. Narrowband reflectance imagery compared with thermal imagery for early detection of plant stress. J. Plant 
imagery for early detection of plant stress. J.Plant Physiol. 148-522.

Carter, G.A. 1998. Reflectance wavebands and indices for remote estimation of photosynthesis and stomatal conductance in pine canopies. Remote Sens. Environ. 63, 61-72.

Chan, K.Y., Zwieten van, B.L., Meszaros, I., Downie, D., Joseph, S. 2007. Agronomic values of green waste biochars as a soil amendments. Aust. J. Soil Res. 45, 437-444.

Corwin, D.L, Lesch, S.M, 2003. Application of soil electrical conductivity to precision agriculture: theory, principles, and guidelines. Agron. J. 95, 455-471.

FFTC. 2001: Application of Rice Husk Charcoal. FFTC Leaflet for Agriculture No. 4. Food and Fertilizer Technology Center, Taipei.

Glaser, B., Lehmann, J., Zech, W. 2002. Ameliorating physical and chemical properties of highly weathered soils in the tropics with charcoal - a review. Biol. Fertil. Soils. 35, 219-230.

Haefele, S.M., Knoblauch, C., Gummert, M., Konboon, Y., Koyama, S, 2009. Black Carbon (Biochar) in Rice-Based Systems: Characteristics and Opportunities In: Woods W. I., Teixeira, W. G., Lehmann J, Steiner C, Winkler Prins A, Rebellato L (Ed.) Amazonian Dark Earths: Wim Sombroek's Vision. Springer Netherlands, 445-463.

Haefele, S.M., Konboon, Y., Wongboon, W., Amarants ,S., Maarifat, A.A., Pfriffer, E.M., Knoblauch, C., 2011. Effects and fate of biochar from rice residues in rice-based systems. Field Crop Res. 121, 430-440.

Hossain, M.K., Strezov, V.K., Chan, Y., Ziolkowski ,A., Nelson, P.F. 2011. Influence of pyrolysis temperature on production and nutrient properties of wastewater sludge biochar. J. Environ. Manage. 92, 223-228
Kimetu, J.M, Lemhann, J. 2010. Stability and stabilzaiton of biochar and green manure in soil with different organic carbon contents. Soil Res. $48,577-585$.

Lee, F.Y 2007. Laboratory Manual for Soil Analysis (in Chinese), New Wun Ching development publishing co., Ltd., 70-75.

Lehmann, J,, Czimczik, C., Laird, D., Sohi, S. 2009. Stability of biochar in the soil. In: Lehmann, J., Joseph, S., (eds) Biochar for environmental management: science and technology. Earthscan Publ., London, pp. 183-205.

Major, J. 2009. A guide to conducting biochar trials. The international biochar initiative. Document version information: www.biochar-international. org.

Milford, M.H 1997. Introduction to Soils and Soil Science Laboratory Exercises. Kendall/Hunt Publishing Company, Dubuque, Iowa. ISBN:07872-3383-8.

Oshio, H., Nii, F., Namioka, H. 1981. Characteristics of Kuntan (rice hull charcoal) as medium of soilless culture. J. Jpn. Soc. Hort. Sci. 50, 231-238.

Peterson, T.A, Blackmer TM, Francis DD, Schepers JS, 2010: Using a chlorophyll meter to improve nitrogen management. G93-1171-A USDA-ARS. Spectrum Technologies, Inc.

Ponamperuma, F.N, 1982: Straw as source nutrient for wetland rice. In: Banta, S., Mendoza, C.V., (eds), Organic matter and rice. Los Baños, The Philippines: IRRI, 117-136.

Rawat, N., Nautiyal, B., Nautiyal, M. 2010. Litter decomposition rate and nutrient release from different forms in a Himalayan alpine ecosystem. The Enrionmetnalist, 30, 279-288. 
Savant, N.K., Datnoff, L.E., Snyder, G.H. 1997. Depletion of plant available silicon in soils: a possible cause of declining rice yields. Commun. Soil Sci. Plant Anal. 28, 1245-1252.

Savant, N.K., Snyder, G.H., Datnoff,L.E 1999. Silicon management and sustainable rice production. Adv. Agron. 58,151-199

Sohi, S., Lopez-Capel, E,. Krull, E., Bol, R. 2009. Biochar, climate change and soil: a review to guide future research. CSIRO Land and Water Science Report.

Stoyle, A. 2011. Biochar production for carbon sequestration. A Major qualifying project. Degree of Bachelor of Science in Chemical Engineering. Worcester Polytechnic Institute. England, 18.
Walkley, A., Black, I.A. 1934. An examination of degtjareff method for determining soil organic matter and a proposed modification of the chromic acid titration method. Soil Science. 37, 29-37.

Williams, N.A., Morse, N.D., Buckman, J.F. 1972. Burning vs. incorporation of rice crop residues. Agronomy J. 64, 467- 468.

Yamato, M., Okimori, Y., Wibowo, I.F., Anshori, S., Ogawa, M. 2006. Effects of the application of charred bark of acacia mangium on the yield of maize, cowpea and peanut, and soil chemical properties in South Sumatra, Indonesia. J. Soil Sci. and Plant Nutr. 52, 489-495. 